\title{
Leakage detection by using transient tests on an experimental looped water distribution network
}

\author{
Uchit Sangroula ${ }^{1}$, Kuk-Heon Han ${ }^{2}$, Kang-Min Koo ${ }^{1}$, Kapil Gnawali ${ }^{1}$, and Kyung-Taek Yum ${ }^{1,}$ * \\ 1 Graduate School of Water Resources, Sungkyunkwan University, Suwon 16419, Korea; uchit@skku.edu; \\ koo00v@skku.edu; kapil@g.skku.edu \\ 2 Smart Water Technology and Consulting, Ltd., Incheon 21315, Korea; kuk0904@daum.net \\ * Correspondence: kwfyum@skku.edu; Tel.: +82-31-290-7645
}

\begin{abstract}
Water is a limited resource that needs to be properly managed and distributed to the evergrowing population of the world. Rapid urbanization and development have drastically increased the overall water demand worldwide. Ageing water distribution networks are vulnerable to deterioration and leakage, thereby causing an estimated annual loss of about 48 trillion liters of water. To address these issues, efficient and reliable leakage detection and management techniques are necessary. In this paper, the results of the experiments performed on a looped water distribution network in AnSeong, Korea are discussed. Transient-based techniques were used and physical data were collected for the detection and localization of leakages in the experimental water pipes. The results obtained from the experiments demonstrated the applicability of transient techniques for leak analysis in looped water distribution networks.
\end{abstract}

Keywords: Water distribution networks, AnSeong, Transient-based techniques, Leak analysis

\section{Introduction}

Water distribution networks are vital infrastructure that are necessary to provide people with sufficient water of appropriate quality. Water losses in water distribution networks can generally be divided into apparent losses (unauthorized consumption, metering inaccuracies, etc.), and real losses (leakage of transmission and/or distribution mains, leakage and overflows at the utility's storage tanks, etc.) [1]. Leakages cause significant waste of water, thereby causing huge economic loss to the water utilities, as well as the potential for water pollution. The amount of water lost from water distribution systems worldwide is large, and is estimated to be around 48 trillion $\mathrm{L}=48$ billion $\mathrm{m}^{3}$ per year [2]. Furthermore, in developing countries, water losses can exceed $50 \%$ of the water produced, causing significant economic problems [3]. Hence, leak detection and localization are of high priority to water utilities and authorities [4], and crucial for the reliable and efficient operation of water distribution systems.

Several different methods and techniques have been presented in the literature for the analysis, detection, and localization of leakages. Conventional water loss studies generally focus on the supply and demand balances for water systems or their subsystems, such as District Metered Areas (DMAs). In such studies, flow rates are primarily used to compute a mass balance to execute the leak analysis and detection, e.g., Ref. [5]. Methods for leak detection and localization include acoustic techniques [6-8], infrared imaging [9], ground penetrating radar [10], and pressure waves and transient analysis [11-16].

When transient condition occurs in a water distribution network, pressure waves propagate within the entire system, until a new steady state is attained. The pressure wave contains important information concerning the condition of the distribution network. The pressure wave propagating through an intact pipe is affected by friction forces, and it progressively and smoothly dampens [17]. Any changes in the pipelines (sediment accumulation, air pockets, leakages, etc.) significantly affect the characteristics of the propagating pressure wave $[11,12,18,19]$. These abrupt changes in the pressure signal can be 
utilized for the detection and localization of leakages in the system [20-24]. However, to detect faults in the system, it is necessary to have full knowledge of the existing characteristics of the system (pipe diameter, pipe length, bends, branches in the network, etc.) [25]. The aim of this paper is to generate transient condition in a looped experimental water distribution network, and use the pressure signal to detect and locate leakages.

\subsection{Governing equations}

The basic equations of continuity and momentum that describe unsteady flow in elastic pipes are [26]:

$$
\begin{aligned}
& \frac{\partial H}{\partial t}+\frac{C^{2}}{g A} \frac{\partial Q}{\partial x}=0 \\
& \frac{\partial H}{\partial x}+\frac{1}{g A} \frac{\partial Q}{\partial t}+\frac{f Q|Q|}{2 g D A^{2}}=0
\end{aligned}
$$

where, $H$ is the piezometric head, $Q$ the discharge, $C$ the pressure wave speed, $g$ the acceleration due to gravity, $A$ the cross-sectional area of pipe, $D$ the internal pipe diameter, $f$ the coefficient of friction, $x$ the distance along the pipe, and $t$ the time.

Equations (1) \& (2) can be transformed into a system of ordinary differential equations along the characteristics line, and solved by the Method of Characteristics (MOC) for pressure head $H$ and discharge $Q$ as [10]:

$$
\begin{aligned}
H_{k}^{i+1} & =\frac{1}{2}\left(H_{k-1}^{i}+H_{k+1}^{i}\right)+\frac{C}{2 g A}\left(Q_{k-1}^{i}-Q_{k+1}^{i}\right)+\frac{C f \Delta t}{4 g D A^{2}}\left(Q_{k+1}^{i}\left|Q_{k+1}^{i}\right|-Q_{k-1}^{i}\left|Q_{k-1}^{i}\right|\right) \\
Q_{k}^{i+1} & =\frac{1}{2}\left(Q_{k-1}^{i}-H_{k+1}^{i}\right)+\frac{g A}{2 C}\left(H_{k-1}^{i}+H_{k+1}^{i}\right)+\frac{C f \Delta t}{4 g D A^{2}}\left(Q_{k-1}^{i}\left|Q_{k-1}^{i}\right|-Q_{k+1}^{i}\left|Q_{k+1}^{i}\right|\right)
\end{aligned}
$$

where, $i$ is the node number, and $\Delta t$ the time steps along the grid.

A leak can be modelled as an orifice, and the discharge $Q_{l}$ can be calculated as [12]:

$$
Q_{l}=C_{d} A_{l} \sqrt{2 g H_{l}}
$$

where, $C_{d}$ is the coefficient of discharge, $A_{l}$ the orifice area, and $H_{l}$ the head.

Equation (6) gives the theoretical formula developed for the estimation of leak size for the maneuver of closure of an inline valve $[4,11]$ used as a reference formula to estimate leak sizes:

$$
q=\frac{Q_{L o}}{Q_{o}}=\frac{\Delta \mathrm{H}_{d}}{\Delta \mathrm{H}}\left[1-\sqrt{1+\frac{\Delta \mathrm{H}+\left(\frac{\Delta \mathrm{H}_{d}}{2}\right)}{\mathrm{H}_{o}-\mathrm{H}_{\text {Lout }}}}\right]^{-1}
$$

where, $H_{o}$ is the steady state piezometric head at the leak section, $H_{\text {Lout }}$ the piezometric head outside the leak to atmosphere, $\Delta H$ the pressure variation at the section where surge is generated and $\Delta H_{d}$ the pressure variation induced by leak.

\section{Materials and Methods}

Multiple tests were performed on the experimental water distribution network in AnSeong, Korea involving different leakage and active loop scenarios. The AnSeong water distribution network contains one reservoir, one pump, 30 pipelines, 25 junctions, and 3 loops. Pressure signal data were collected during each individual experiment for both steady and unsteady conditions, with and without the presence of leak in the system. 


\subsection{Experimental Setup}

Figure 1 shows that the constructed experimental water distribution consists of Ductile Iron pipes having an internal diameter of $80 \mathrm{~mm}$. The total length of the entire system is $356 \mathrm{~m}$, and the water is supplied to the system by a pump with a head of $15 \mathrm{~m}$, with the total inflow in the distribution network being $12.96 \mathrm{~m}^{3} / \mathrm{h}$. Figure 2 shows that three leakage points were simulated in the distribution network by opening inline valves each with a diameter of $20 \mathrm{~mm}$.

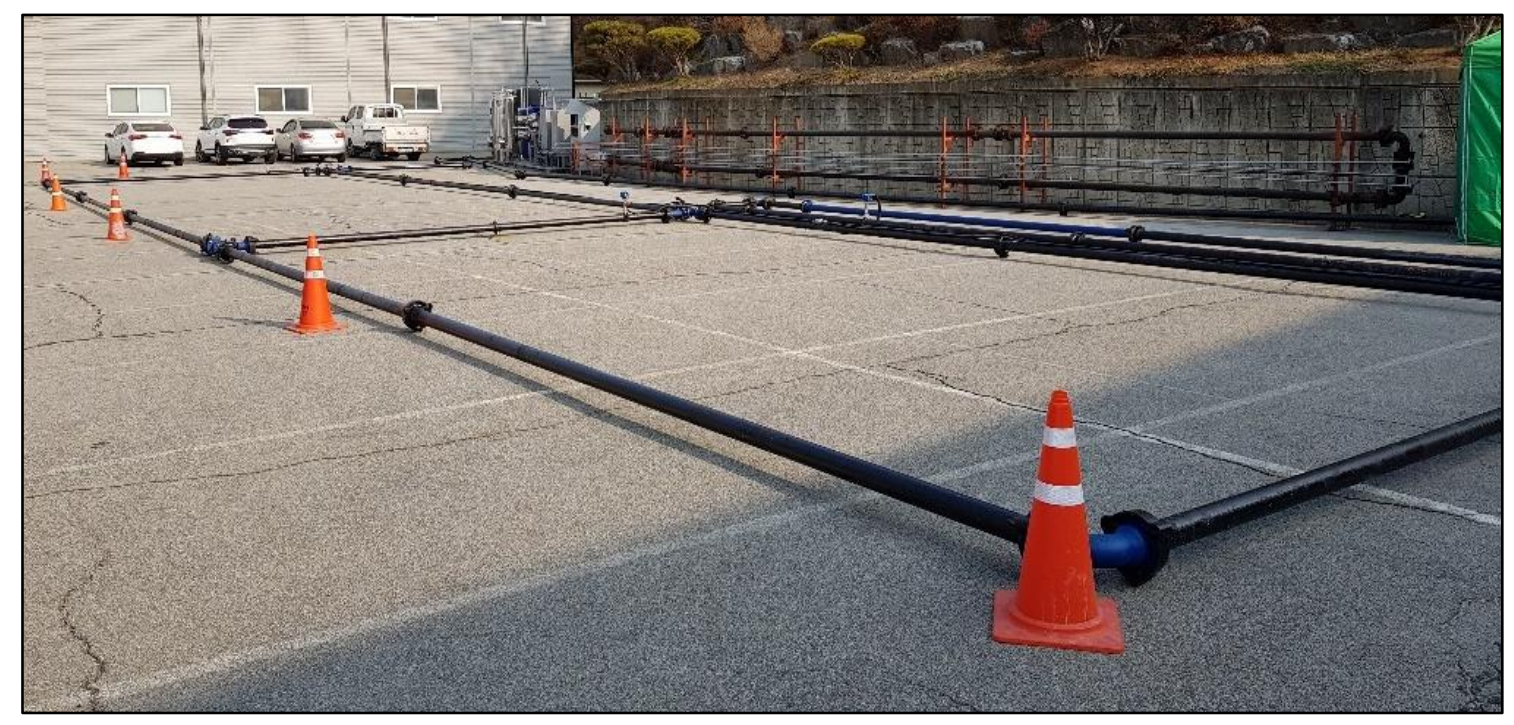

Figure 1. The AnSeong experimental water distribution network.

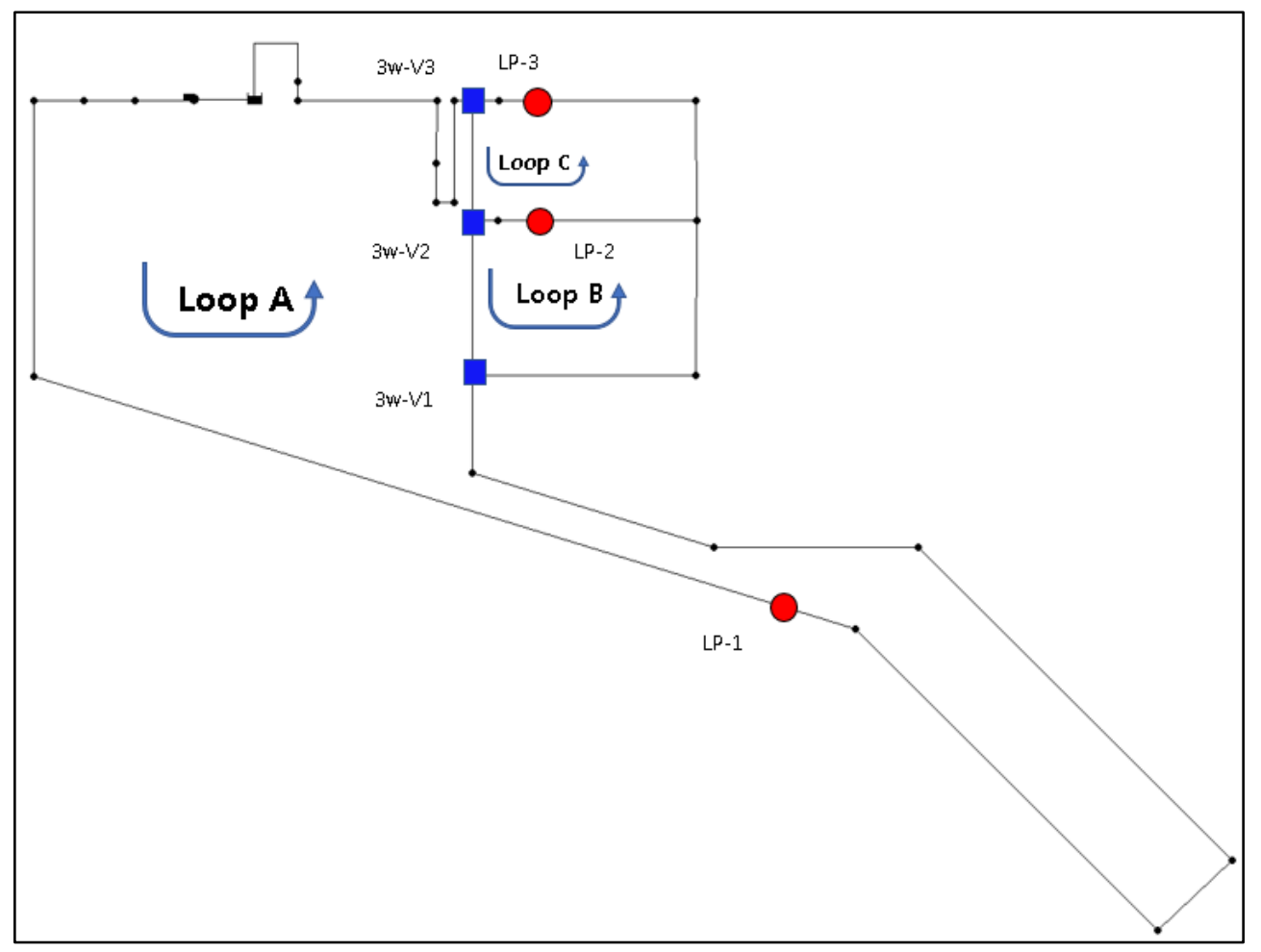

Figure 2. The experimental water network showing leakage points and three-way valves.

Multiple pressure transducers were installed at different locations in the distribution system to collect the pressure signal generated during a transient event. The pressure signal was generated in the system by the quick closure of the inline valve, present at each leak point. Pressure data was collected during normal flow condition, during the leaking 
condition, and most importantly, during the transient condition. All the pressure data collected by the pressure transducers were passed through a GL220 data logger, and were collected on computer. The data collected during the experiment were analyzed.
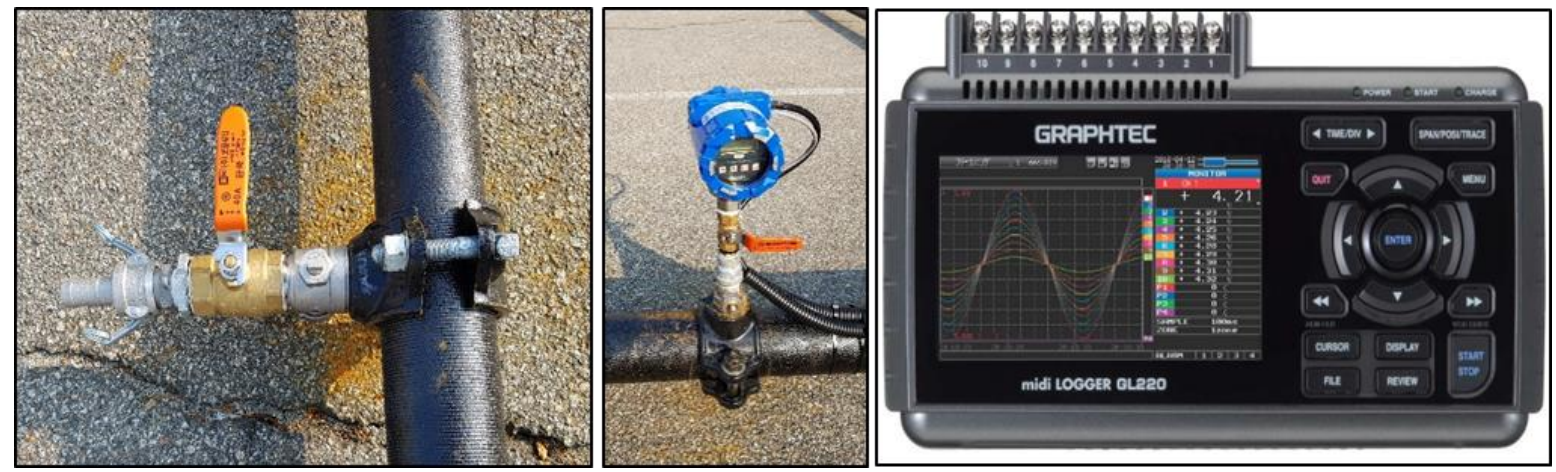

Figure 3. Valve for Leak and Transient Simulation, Pressure Transmitter, and Data Logger.

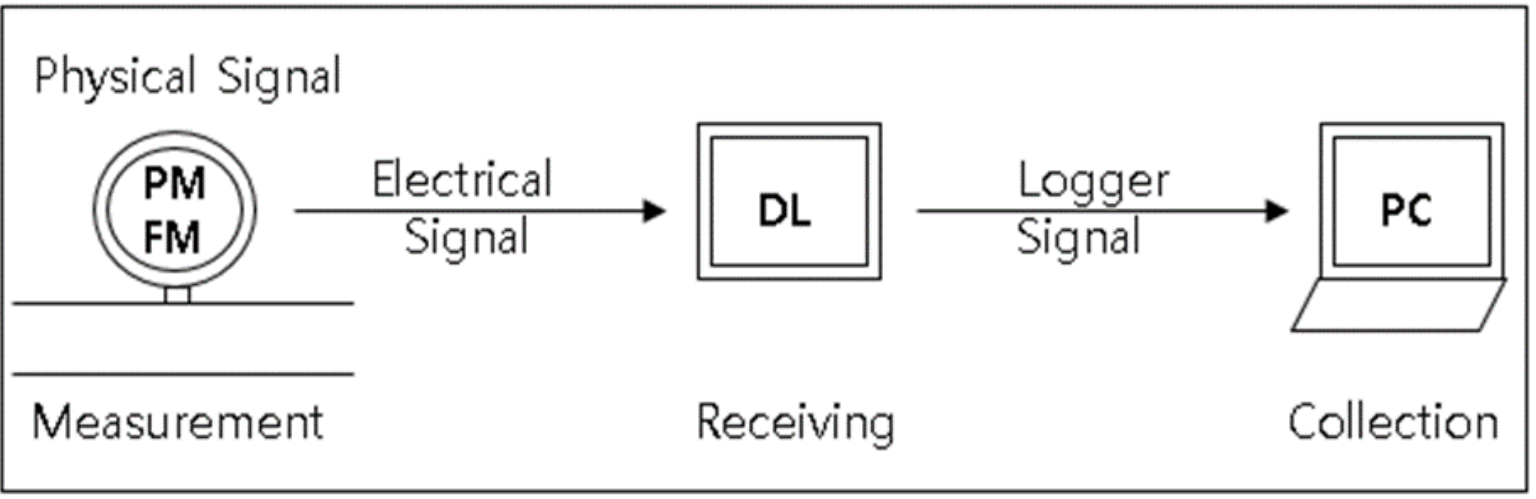

Figure 4. Pressure signal measurement and collection.

The range of the pressure transducers installed in the system was (0 to 20) bar. The collected pressure signal was transferred as an electrical signal to the data logger with a range of (1 to 5) V, and collected in computer for further analysis.

\section{Results and discussion}

Table 1 summarizes the localization of leakage points and the estimation of the quantity of leakage flow from the leak points from the multiple transient tests performed during the AnSeong experiments. (Note that one of the leak points was used for the quick closure of valve to generate pressure waves in the system).

Table 1. Leak localization and assessment by using transient test.

\begin{tabular}{cccccc}
\hline $\begin{array}{c}\text { Leak } \\
\text { point }\end{array}$ & $\begin{array}{c}\text { Actual leak } \\
\text { distance (m) }\end{array}$ & $\begin{array}{c}\text { Total } \\
\text { discharge } \\
\text { (Lps) }\end{array}$ & $\begin{array}{c}\text { Leak } \\
\text { discharge } \\
\text { (Lps) }\end{array}$ & $\begin{array}{c}\text { Calculated } \\
\text { leak distance } \\
(\mathbf{m})\end{array}$ & $\begin{array}{c}\text { Error } \\
\mathbf{( \% )}\end{array}$ \\
\hline LP1 & 94.1 & 13.01 & 3.08 & 87.91 & 6.19 \\
LP2 & 15.5 & 12.96 & 2.35 & 14.06 & 9.29 \\
\hline
\end{tabular}




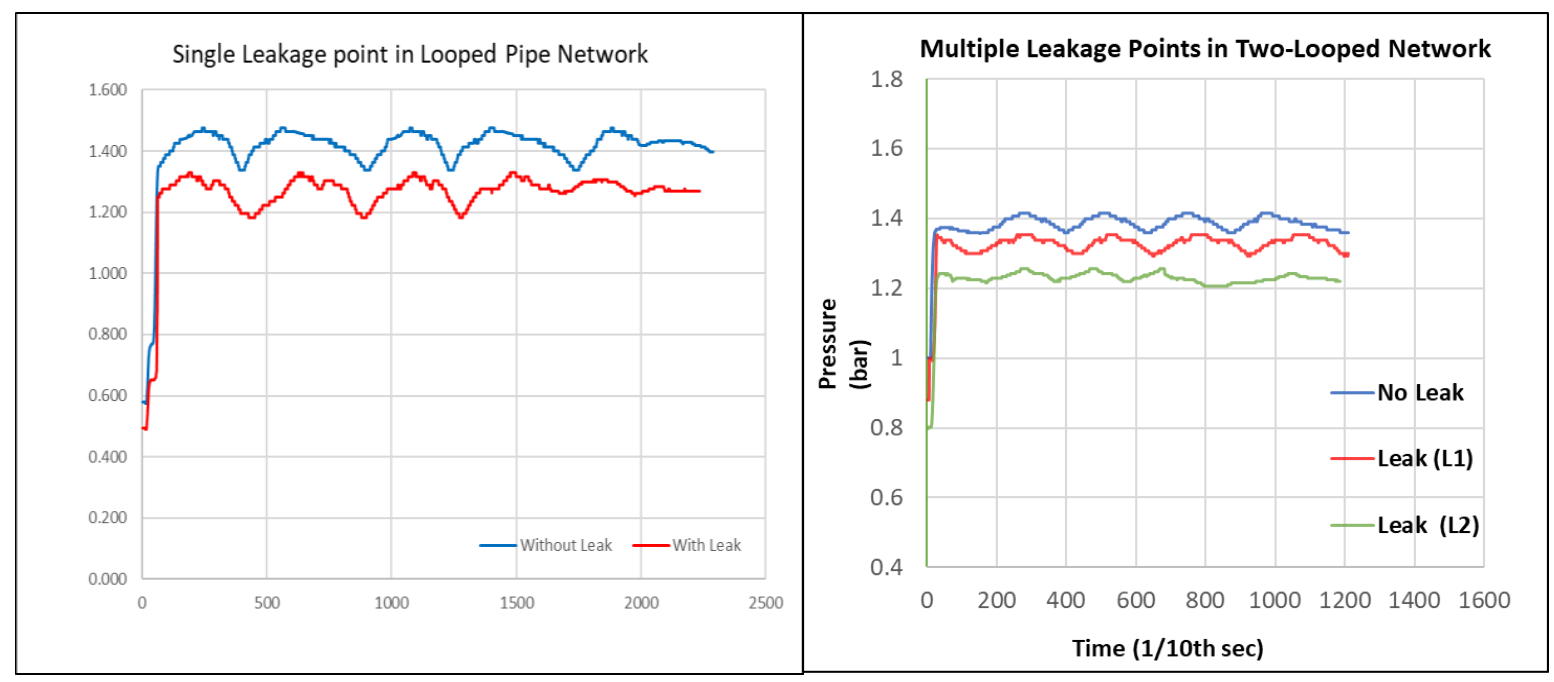

Figure 5. Pressure signal measured with and without the presence of leak in the network

Figure 5 presents the nature of the pressure wave signal after the generation of water hammer from the quick closure of an inline valve, with and without the presence of leak in the experimental water distribution network. The figure illustrates the effect of leak points on the behavior of the generated pressure wave.

\section{Conclusions}

This paper reports the results of the transient tests carried out on an experimental two-looped water distribution network in AnSeong, Korea. Transient tests were conducted for the detection, localization, and estimation of leakage in the water distribution network. Transients were generated by the quick closure of inline valve from one of the leak points in the network. The behavior of the generated, and then reflected pressure wave signal was analyzed and utilized for leakage detection and localization.

Leakage points in the distribution network were identified in most cases with reasonable error. The reflection of the pressure waves from leaks must be isolated from the reflections occurring from network bends and junctions. For this, knowledge of the existing water distribution network is important. Overall, transient testing can be utilized to identify leaks in the water distribution network containing loops, and can be applicable for network diagnosis and monitoring.

Supplementary Materials: Not applicable.

Author Contributions: Uchit Sangroula performed the experiments for the research work, analyzed the data, and wrote the manuscript of this study; Kapil Gnawali assisted during experiments; KukHeon Han managed the experiment site; Kang-Min Koo and Kyung-Taek Yum provided significant suggestions on the methodology and structure of the manuscript. All authors have read and approved the final manuscript

Funding: This Research has been performed as Development of Water and Sewage Innovation Technology Program of ARQ202001302001 supported by Korea Ministry of Environment.

Institutional Review Board Statement: Not applicable.

Informed Consent Statement: Not applicable.

Data Availability Statement: Datasets that are restricted and not publicly available.

Conflicts of Interest: The authors declare no conflict of interest. 
1. Lambert, A. Assessing non-revenue water and its components: a practical approach. Water 2003, 21, 50-51.

2. Liemberger, R.; Marin, P. The challenge of reducing non-revenue water (NRW) in developing countries-how the private sector can help: a look at performance-based service contracting; The World Bank: 2006.

3. Mambretti, S.; Orsi, E. Genetic algorithms for leak detection in water supply networks. Urban Water 2012, 63-71.

4. Covas, D.; Stoianov, I.; Ramos, H.; Graham, N.; Maksimovic, C. The dissipation of pressure surges in water pipeline systems. Pumps, electromechanical devices and systems applied to urban management 2003, 2, 711-9.

5. Buchberger, S.G.; Nadimpalli, G. Leak estimation in water distribution systems by statistical analysis of flow readings. Journal of water resources planning and management 2004, 130, 321-329.

6. Tafuri, A.N. Locating leaks with acoustic technology. Journal-American Water Works Association 2000, 92, 57-66.

7. Hunaidi, O.; Chu, W.T. Acoustical characteristics of leak signals in plastic water distribution pipes. Applied Acoustics 1999, 58, 235-254.

8. Brennan, M.; Joseph, P.; Muggleton, J.; Gao, Y. The use of acoustic methods to detect water leaks in buried water pipes. Water and Sewerage Journal 2006, 1, 11-14.

9. Hunaidi, O.; Chu, W.; Wang, A.; Guan, W. Detecting leaks in plastic pipes. Journal-American Water Works Association 2000, 92, 82-94.

10. Hunaidi, O.; Giamou, P. Ground-penetrating radar for detection of leaks in buried plastic water distribution pipes. International Conference on Ground Penetrating Radar 1998, 783-786.

11. Brunone, B. Transient test-based technique for leak detection in outfall pipes. Journal of water resources planning and management 1999, 125, 302-306.

12. Brunone, B.; Ferrante, M. Detecting leaks in pressurised pipes by means of transients. Journal of hydraulic research 2001, 39, 539547.

13. Mpesha, W.; Gassman, S. L.; Chaudhry, M. H. Leak detection in pipes by frequency response method. Journal of Hydraulic Engineering 2001, 127, 134-147.

14. Ferrante, M.; Brunone, B. Pipe system diagnosis and leak detection by unsteady-state tests. 1. Harmonic analysis. Advances in Water resources 2003, 26, 95-105.

15. Misiunas, D.; Vítkovský, J.; Olsson, G.; Simpson, A.; Lambert, M. Pipeline break detection using pressure transient monitoring. Journal of Water Resources Planning and Management 2005, 131(4), 316-325.

16. Taghvaei, M.; Beck, S. B. M.; Staszewski, W. J. Leak detection in pipelines using cepstrum analysis. Measurement Science and Technology 2006, 17(2), 367.

17. Brunone, B.; Golia, U. M.; Greco, M. Effects of two-dimensionality on pipe transients modeling. Journal of Hydraulic Engineering 1995, 121, 906-912.

18. Jönsson, L. Detection of leaks using pressure transients. Report, Univ. of Lund, Sweden 1994.

19. Liggett, J. A.; Chen, L. C. Inverse transient analysis in pipe networks. Journal of Hydraulic Engineering 1994, 120(8), $934-955$.

20. Covas, D.; Ramos, H. Case studies of leak detection and location in water pipe systems by inverse transient analysis. Journal of Water Resources Planning and Management 2010, 136(2), 248-257.

21. Ghazali, M. F.; Beck, S. B. M.; Shucksmith, J. D.; Boxall, J. B.; Staszewski, W. J. Comparative study of instantaneous frequencybased methods for leak detection in pipeline networks. Mechanical Systems and Signal Processing 2012, 29, 187-200.

22. Stephens, M. L.; Lambert, M. F.; Simpson, A. R.; Vitkovsky, J. P. Calibrating the water-hammer response of a field pipe network by using a mechanical damping model. Journal of Hydraulic Engineering 2011, 137(10), 1225-1237.

23. Duan, H. F.; Lee, P. J.; Ghidaoui, M. S.; Tung, Y. K. Leak detection in complex series pipelines by using the system frequency response method. Journal of Hydraulic Research 2011, 49(2), 213-221.

24. Lee, P. J.; Vítkovský, J. P.; Lambert, M. F.; Simpson, A. R.; Liggett, J. Leak location in pipelines using the impulse response function. Journal of Hydraulic Research 2007, 45(5), 643-652.

25. Meniconi, S.; Brunone, B.; Frisinghelli, M.; Mazzetti, E.; Larentis, M.; Costisella, C. Safe transients for pipe survey in a real transmission main by means of a portable device: The case study of the Trento (I) supply system. Procedia Engineering 2017, 186, 228-235.

26. Wylie, E. B.; Streeter, V. L.; Suo, L. Fluid transients in systems, Englewood Cliffs, NJ: Prentice Hall, 1993, pp. 464. 